\title{
Actividad antioxidante de los musgos Breutelia subdisticha, Leptodontium viticulosoides y Pylaisia falcata
}

\author{
Antioxidant Activity of the Mosses Breutelia subdisticha, Leptodontium \\ viticulosoides and Pylaisia falcata
}

\author{
Nathaly Téllez-Rocha ${ }^{1}$, Bibiana Moncada ${ }^{2}$, Luis Miguel Pombo-Ospina ${ }^{3}$ y Oscar E. Rodríguez-Aguirre ${ }^{4}$
}

\begin{abstract}
Resumen
Los musgos son utilizados por muchas culturas para tratar diferentes enfermedades, probablemente por sus compuestos bioactivos, algunos de los cuales pueden presentar actividad antioxidante. Esta investigación evaluó la actividad antioxidante (AA) de Breutelia subdisticha (Hampe) A. Jaeger, Leptodontium viticulosoides (P. Beauv.) Wijk \& Margad. y Pylaisia falcata Schimp., a partir de extractos de diclorometano y etanólicos, mediante los métodos 2,2-difenil-1-picrilhidracilo (DPPH*) y ácido 2,2/-azino-bis-3etilbenzotiazolin-6-sulfónico (ABTS ${ }^{*+}$ ). A los extractos obtenidos mediante la técnica Soxhlet se les determinó la concentración inhibitoria $\left(\mathrm{IC}_{50}\right)$ y la actividad antioxidante relativa (\%AAR), con posteriores análisis estadísticos de ANOVA y post-hoc de Tukey. Los extractos etanólicos presentaron mayor capacidad antioxidante que los de diclorometano. Por el método DPPH* los extractos etanólicos mostraron una \%AAR respecto al ácido ascórbico de 3.06 para L. viticulosoides, 177.00 para B. subdisticha y 141.66 para P. falcata; mientras que con el método $\mathrm{ABTS}^{*+}$ la\%AAR con respecto al ácido ascórbico fue de 1.75 para L. viticulosoides, 139.17 para B. subdisticha y 120.22 para $P$. falcata. Como conclusión, L. viticulosoides exhibió la mejor actividad antioxidante, por lo cual se sugiere continuar con su investigación y lograr una aplicación farmacológica de origen natural.
\end{abstract}

Palabras clave: Palabras clave: Briófitos, antioxidante, radicales libres, $\mathrm{DPPH}^{*}$ y ABTS*+

\begin{abstract}
Mosses are used by many cultures to treat different diseases, probably due to their bioactive compounds, some of which may have antioxidant activity. This research evaluated the antioxidant activity (AA) of the species Breutelia subdisticha (Hampe) A. Jaeger, Leptodontium viticulosoides (P. Beauv.) Wijk \& Margad. and Pylaisia falcata Schimp., from dichloromethane and ethanolic extracts, using the 2,2-diphenyl-1-picrylhydracil (DPPH*) and 2,2-azino-bis-3-ethylbenzothiazoline-6-sulfonic acid (ABTS ${ }^{*+}$ ) methods. Inhibitory concentration $\left(\mathrm{IC}_{50}\right)$ and relative antioxidant activity (\% AAR) were determined from the extracts obtained using the Soxhlet technique, with subsequent statistical analysis (ANOVA and Tukey's post-hoc). The ethanolic extracts exhibited higher antioxidant capacity than those of dichloromethane. By the DPPH* method the ethanolic extracts showed a relative antioxidant activity with respect to ascorbic acid for $L$. viticulosoides 3.06, B. subdisticha 177.00 and P. falcata 141.66 . Using ABTS ${ }^{*+}$ method, ethanolic extracts showed a relative antioxidant activity with respect to ascorbic acid for $L$. viticulosoides 1.75, B. subdisticha 139.17 and P. falcata 120.22. In conclusion, L. viticulosoides exhibited the best antioxidant activity, therefore, we propose to continue with its research, in order to achieve a pharmacological application from a natural source.
\end{abstract}

Keywords: Bryophytes, antioxidant activity, free radicals, $\mathrm{DPPH}^{*}$ and $\mathrm{ABTS}^{*+}$

Recepción: 24-feb-2021

Aceptación: 29-jun-2021

\footnotetext{
${ }^{1}$ Universidad Distrital Francisco José de Caldas, Bogotá, Colombia. ORCID: 0000-0002-0717-0585.

Correo electrónico: nntellezr@ correo.udistrital.edu.co

${ }^{2}$ Universidad Distrital Francisco José Caldas, Bogotá, Colombia y Botanischer Garten und Botanisches Museum, Freie Universität Berlin, Berlin, Germany. ORCID: 0000-0001-9984-2918. Correo electrónico: lbmoncada@udistrital.edu.co

${ }^{3}$ Fundación Universitaria Juan N. Corpas, Bogotá, Colombia. ORCID: 0000-0002-7277-1838.

Correo electrónico: miguel.pombo@juanncorpas.edu.co

${ }^{4}$ Universidad El Bosque, Bogotá, Colombia, Facultad de Ingeniería. Grupo de Investigación CHOC-IZONE.

ORCID: 0000-0002-5934-0451, Correo electrónico: rodriguezoscare@ unbosque.edu.co
} 


\section{Introducción}

El rol fisiológico de los antioxidantes es prevenir el daño a los componentes celulares que surgen como consecuencia de reacciones químicas que involucran radicales libres [1,2]. Son inhibidores del proceso oxidativo y constituyen la primera línea de defensa contra el daño generado por los radicales libres, siendo esenciales para mantener una salud óptima [3]. Los antioxidantes son una serie de compuestos químicos pertenecientes a metabolitos secundarios tales como flavonoides, ácido ascórbico (Vitamina C), carotenoides (Vitamina A) y tocoferoles (Vitamina E) [4-7].

Los musgos pertenecen a la división Bryophyta, el grupo más complejo entre las briofitas [8], que a su vez conforma el clado más diverso, con aproximadamente 12,000 especies [9], en su gran mayoría de amplia distribución [10-12]. Son componentes florísticos conspicuos en todos los hábitats terrestres adecuados para su crecimiento, transitando por el frío antártico hasta los exuberantes bosques tropicales [13]. Colombia goza de una gran diversidad briológica, con 932 especies de musgos, 704 hepáticas y 15 antocerotes reportadas [14, 15]. Dicha diversidad se concentra principalmente en la región Andina del país, la cual ocupa aproximadamente el $25 \%$ de la nación y contiene más del 90\% de las especies de musgos [16].

El aprovechamiento de las briofitas como plantas medicinales ha sido común y frecuente en China e India y entre los nativos americanos desde tiempos antiguos [17]. Existen registros desde la etnobriología que exponen una serie de usos muy heterogéneos, entre los cuales están aliviar quemaduras, contusiones, heridas, fracturas [18-20], detener hemorragias, curar enfermedades oculares $[19,21$, 22], combatir infecciones fúngicas, aprovechar propiedades anti apetitosas [21, 23], tratar enfermedades cardiovasculares y crisis nerviosas, reducir inflamación, y hasta usos como diurético, laxante, coagulante, contra el resfriado común. Además, se reportan propiedades antitumorales [5, 17-25], actividades antiriníticas, antipiréticas, anticonceptivas, antiflogísticas, hemostáticas, como antídotos, y tratando la ictericia, faringitis, amigdalitis, mastitis, neumonía, entre otras [26-29]. Incluso, algunos musgos pueden servir como alimento para humanos al tener un sabor dulce [30].

La aplicación de carácter farmacéutico tiene su razón en las sustancias biológicamente activas presentes en las briofitas [27, 31]. Estos se han descuidado durante mucho tiempo, porque los musgos son generalmente pequeños y difíciles de recolectar, siendo difícil la recolección de una especie particular en altas cantidades sin poner en peligro las poblaciones naturales; además, el muestreo puede causar que se entremezclen otras especies en las muestras. Por lo tanto, solo un pequeño porcentaje de taxones ha sido analizado desde el punto de vista fitoquímico [29, 30, 32, 33].

Entre los metabolitos secundarios de los musgos se detectan flavonoides, terpenoides, esteroides, compuestos aromáticos simples, cromanoles, alcaloides, derivados del bibencilo, del ácido ftálico, de cromonas, de p-terfenilo, cumarinas, saponinas, benzonaftoxanthenonas, compuestos que contienen nitrógeno y, además, acetogeninas, antocianinas, vitamina B2, triglicéridos y ácidos grasos altamente insaturados [11, 27, 30, 34-40]. También se detectaron compuestos volátiles, oxilipinas, fenoles, azúcares reductores, glucósidos, taninos y sanioninas, entre otros [41-46]. En virtud de la presencia diversa de metabolitos secundarios, se logran determinar compuestos bioactivos, muchos de los cuales muestran una variedad excepcional de actividades y propiedades medicinales [27]. De ese modo, a los musgos se confieren actividades antifúngicas, antivirales, antibacterianas, citotóxicas, antiinflamatorias [22,23,43,47-51] y actividades anticancerígenas y antitumorales [25, 30, 52-54]. Adicionalmente, los musgos disponen de una actividad antioxidante [23, 32, 55-66], la cual se ve influenciada en algunos casos debido a distintos tipos de estrés fisiológico, ya sea por adquisición de metales pesados, desecación, choque térmico, radiación, o salinidad [24, 67-69].

En la actualidad, alrededor de un 5\% del total de la brioflora mundial se ha estudiado químicamente [29]; entre estos estudios, los musgos, aunque más diversos que las hepáticas, han sido relativamente menos explorados en cuanto a sus metabolitos secundarios [39, 70-72]. En Colombia, los estudios 
de actividad biológica en musgos son exiguos. Sin embargo, en las últimas décadas se han realizado investigaciones determinando los principales metabolitos secundarios, la actividad antimicrobiana y la capacidad citotóxica del musgo Polytrichum juniperinum Hedw. [73]. Además, fue evaluada la capacidad antioxidante de los extractos totales de los musgos: Breutelia chrysea (Müll. Hal.) A. Jaeger, Dicranum frigidum Müll. Hal., Hypnum amabile (Mitt.) Hampe, Leptodontium luteum (Taylor) Mitt., Sphagnum sp. y Thuidium peruvianum Mitt. [74]. Pereañez et al. (2010) [75] examinaron el efecto de los extractos de 36 plantas entre las cuales se incluyeron seis especies de musgos (Breutelia chrysea, Dicranum frigidum, Leptodontium luteum, Sphagnum recurvum P. Beauv., Sphagnum sp. yThuidium peruvianum) sobre algunas actividades inducidas por el veneno total de la serpiente Bothrops asper Garman. El trabajo más reciente es RodríguezRodríguez et al. (2012) [76], donde se evaluó la actividad antibacteriana de extractos etanólicos de los musgos Hypnum amabile y Sphagnum magellanicum Brid y de las hepáticas Metzgeria decipiens (C. Massal.) Schiffn. y Trichocolea tomentosa (Sw.) Gottsche.

En consecuencia, éste estudio pretende realizar un aporte al conocimiento sobre la actividad biológica de las briofitas de Colombia, contribuyendo en la investigación de antioxidantes naturales [66]. El objetivo principal fue la evaluación de la actividad antioxidante de extractos de musgos terrestres representativos de los bosques subandinos alrededor de Bogotá D.C., considerando tres especies de diferentes grupos filogenéticos: Breutelia subdisticha (Hampe) A. Jaeger (familia Bartramiaceae, Orden Bartramiales), Leptodontium viticulosoides (P. Beauv.) Wijk \& Margad. (familia Pottiaceae, orden Pottiales) y Pylaisia falcata Schimp. (familia Hypnaceae, orden Hypnales). El segundo objetivo fue la comparación de dos métodos de extracción (etanólico y diclorometano) y dos métodos de medida de actividad antioxidante, $\mathrm{DPPH}^{*}$ (2,2-difenil-1picrilhidracilo) y ABTS $^{*+}$ (Acido 2,2'-Azino-bis3-Etilbenzotiazolin-6-Sulfonico), los cuales se basan en su capacidad para bloquear, atenuar o secuestrar radicales libres [77, 78, 79]. Ambos ensayos están basados en la transferencia de electrones. DPPH* es un radical nitrogenado orgánico y estable y posee un intenso color púrpura. La capacidad antioxidante se basa en la disminución de color, medida a $515 \mathrm{~nm}$, por acción de un compuesto antioxidante, monitoreado espectrofotométricamente [80, 81]. Por su parte, el radical ABTS $^{*+}$ se basa en la capacidad antioxidante para secuestrar aniones radicales de larga vida. En el ensayo el ABTS $^{*+}$ es oxidado por radical peróxido u otro oxidante [82-84] hasta formar el radical catiónico. Este método se basa en la capacidad de las moléculas antioxidantes (Trolox) para saciar la larga vida $\mathrm{ABTS}^{*+}$, un cromóforo azulverde, medida a $754 \mathrm{~nm}$, monitoreado igualmente mediante espectrofotometría $[80,85,86]$.

\section{Materiales y métodos}

\subsection{Material vegetal}

Las especies seleccionadas para este estudio fueron los musgos Breutelia subdisticha (Bartramiaceae), Leptodontium viticulosoides (Pottiaceae) y Pylaisia falcata (Hypnaceae). Estas especies presentan una amplia distribución: B. subdisticha en el Neotrópico, desde México hasta Perú y el sureste de Brazil; L. viticulosoides en todo el trópico incluso las fajas subtropicales a subtemperadas en Norteamérica, Suráfrica, Asia y Australia; y Pylaisia falcata con una distribución supuestamente anfi-Pacífica, aunque mayormente ocurre en los Andes y las Cordilleras Centroamericanas hasta el centro de México, mientras los reportes de Asia son cuestionables. En Colombia, las tres especies se reconocen para la región de los Andes y la Sierra Nevada de Santa Marta en elevaciones desde los 1150 a $3680 \mathrm{~m}$, en los departamentos de Arauca, Antioquia, Boyacá, Caldas, Casanare, Cauca, Cundinamarca, Magdalena, Nariño, Norte de Santander, Putumayo, Risaralda, Santander y Valle del Cauca $[14,16]$.

La recolección de los musgos motivo de estudio se realizó entre los meses de abril y junio de 2019, siguiendo el protocolo de Churchill \& Linares [16], en el Parque Ecológico Distrital Entrenubes, ubicado en los cerros surorientales de la ciudad de Bogotá D.C. Este parque cuenta con un área de 627 hectáreas, entre los 2600 a $3100 \mathrm{~m}$. Las 
coordenadas, sustrato y altura exactos de los musgos recolectados fueron: 453'90.1'” N, 740.9'81.2”W, suelo, $2650 \mathrm{~m}$ (Breutelia subdisticha), 4'53'42.2”'N, 740.9'56.2'W, suelo, $2652 \mathrm{~m}$ (Leptodontium viticulosoides) y $4^{\circ} 54^{\prime} 22.9^{\prime \prime} \mathrm{N}, 74^{\circ} 10^{\prime} 02.2^{\prime \prime} \mathrm{W}$, suelo, $2820 \mathrm{~m}$ (Pylaisia falcata). Para las tres especies se recolectó solamente la fase gametofítica ( $\mathrm{sin}$ esporófitos). Una vez recolectado, se procedió a trasladar el material al laboratorio, para separar especies entremezcladas y material que no correspondiera a los musgos (suelo, materia orgánica, etc.). Posteriormente el material se dejó deshidratar a temperatura ambiente durante 20 días. Se obtuvo de masa inicial para B. subdisticha 50.00 g, para L. viticulosoides 38.78 g y para $P$. falcata $17.10 \mathrm{~g}$.

La identificación taxonómica fue realizada en el Herbario José Jerónimo Triana (HJJT) por un especialista. Muestras representativas fueron depositadas en el mismo herbario, con los códigos de recolección 2325, 2326 y 2327, respectivamente (Tabla Suplementaria S1).

\subsection{Preparación de extractos}

Para la extracción total de los compuestos químicos presentes, se siguió el protocolo de Asakawa \& Ludwiczuk [33]. Para ello, los musgos previamente deshidratados fueron triturados de forma manual. Seguidamente se empleó la técnica de extracción "Soxhlet", en donde se introdujo en el equipo Soxleth separadamente el material de cada musgo (B. subdisticha: $50.00 \mathrm{~g}$; L. viticulosoides: 38.78 g; P. falcata: 17.10 g) y se inició la extracción con solvente de media polaridad $\left(\mathrm{CH}_{2} \mathrm{Cl}_{2}\right)$, con posterior extracción con solvente de alta polaridad (EtOH). El tipo de extracción fue sólido-líquido, con duración de 8 días, a temperatura de ebullición según el solvente. Una vez culminados los ciclos correspondientes, los extractos se concentraron en el rotaevaporador a una presión de 760 mbar para el extracto diclorometano y 200 mbar para el extracto etanólico, a una temperatura de $40^{\circ} \mathrm{C}$ y $70 \mathrm{rpm}$, obteniéndose los extractos deseados.

\subsection{Preparación de soluciones patrón}

Como soluciones patrón se realizaron preparaciones del radical $\mathrm{DPPH}^{*}$, radical $\mathrm{ABTS}^{*+}$, trolox, rutina y ácido ascórbico. Estas soluciones se prepararon de la siguiente manera.

Preparación radical $D P P H^{*}$ : se disolvieron (0.1 mMolar) 3.94 mg de DPPH* (2,2-difenil-1picrilhidracilo), de la casa comercial Sigma-Aldrich, en $100 \mathrm{~mL}$ de metanol grado analítico. La solución se dejó reaccionar a temperatura ambiente durante 24 horas en la oscuridad. Posteriormente fueron preparadas soluciones de trabajo hasta obtener una absorbancia de $0.750 \pm 0.050$ para todos los casos, a una longitud de onda de $517 \mathrm{~nm}$.

Preparación del radical ABTS ${ }^{*+}$ : se disolvieron (7 mMolar) $360 \mathrm{mg}$ de ABTS $^{*+}$ (Ácido 2,2'Azino-bis-3-Etilbenzotiazolin-6-Sulfonico), de la casa comercial Sigma-Aldrich, en $10 \mathrm{~mL}$ de agua desionizada: Luego se adicionó $66.23 \mathrm{mg}$. de persulfato de potasio $\left(\mathrm{K}_{2} \mathrm{~S}_{2} \mathrm{O}_{8}\right)$, (2.45 mMolar) aforándose a $100 \mathrm{ml}$ de solución total con metanol. La solución se dejó reaccionar a una temperatura de $3{ }^{\circ} \mathrm{C}$ durante 48 horas en la oscuridad. Posteriormente fueron preparadas soluciones de trabajo hasta obtener una absorbancia de $0.750 \pm$ 0.050 para todos los casos, a una longitud de onda de $754 \mathrm{~nm}$.

Preparación de trolox: se preparó una solución stock (3.995 mMolar) en metanol disolviendo 10 mg de ácido 6-hidroxi-2,5,7,8-tetrametilcromo-2carboxílico 97\% (trolox), de la casa comercial Acros Organics, en $10 \mathrm{~mL}$ de metanol.

Preparación de rutina: se preparó una solución stock 1000 ppm (1.637 mMolar) de metanol disolviendo $10 \mathrm{mg}$ de rutina, en $10 \mathrm{~mL}$ de metanol.

Preparación de ácido ascórbico: se preparó una solución stock 1000 ppm (5.68 mMolar), disolviendo $10 \mathrm{mg}$ de ácido ascórbico (Vitamina C) en $10 \mathrm{~mL}$ de metanol.

\subsection{Metodología para los ensayos}

Curva de referencia del ácido ascórbico y rutina para $D P P H^{*}$ : en celdas de volumen reducido de 1.5 $\mathrm{ml}$ se prepararon 7 diluciones de 8 a 20 ppm para el 
ácido ascórbico y 9 diluciones entre 4 a 20 ppm de rutina, leyendo en espectrofotómetro visible a 517 $\mathrm{nm}$, con intervalos de 10 minutos hasta 60 minutos.

Curva de referencia del ácido ascórbico, trolox y rutina para $A B T S^{*+}$ : en celdas de volumen reducido de $1.5 \mathrm{ml}$ se prepararon 4 diluciones de 1 a $4 \mathrm{ppm}$ para el ácido ascórbico y trolox y 9 diluciones entre 4 a 20 ppm de rutina, leyendo en espectrofotómetro visible a $754 \mathrm{~nm}$, con intervalos de 10 minutos hasta 60 minutos.

Actividad captadora de radicales libres $D P P H^{*}$ y $A B T S^{*+}$ : se prepararon 9 diluciones entre $40 \mathrm{y}$ $200 \mathrm{ppm}$ de los extractos de las especies (Breutelia subdisticha, Leptodontium viticulosoides y Pylaisia falcata), utilizado el respectivo antioxidante $\mathrm{DPPH}^{*}$ o ABTS $^{*+}$ midiendo la absorbancia cada $10 \mathrm{~min}$ hasta 60 min. Para luego determinar los porcentajes de captación de radicales libres. El experimento se realizó por triplicado. Para los dos métodos el porcentaje de captación se calculó con base en la siguiente ecuación: \% de Captación $=[(\mathrm{A}$ inicial $-\mathrm{A}$ final) / (A inicial)] x 100.

\subsection{Determinación de la Concentración Media Inhibitoria IC $_{50}$}

De acuerdo con la ecuación de la curva logarítmica de la concentración inhibitoria, donde $Y=m \ln (x)+$ $b$ obtenida de los (\%) porcentajes de captación de radicales libres con respecto a sus concentraciones, se obtuvieron los valores del intercepto $(b)$ y la pendiente $(m)$, y tomando $Y=50$ se determinó a $(x)$ que corresponde a la $\mathrm{IC}_{50}$.

\subsection{Actividad antioxidante relativa (\% AAR)}

La actividad antioxidante relativa se determinó al obtener el cociente de la $\mathrm{IC}_{50}$ de cada extracto con respecto a la $\mathrm{IC}_{50}$ de cada patrón.

La experimentación se llevó a cabo en el laboratorio de Fitoquímica de la Fundación Universitaria Juan N. Corpas. Bogotá, Colombia.

\subsection{Análisis estadístico}

Los resultados de actividad antioxidante obtenidos por los dos métodos $\mathrm{DPPH}^{*}$ y $\mathrm{ABTS}^{*+}$ (Tabla Suplementaria S2) fueron analizados por Análisis de Varianza a una vía (ANOVA) y comparación post-hoc de Tukey. Se consideraron diferencias significativas para $\mathrm{p}<0.05$. Para el análisis, se utilizó el programa estadístico Minitab 19. En el ANOVA, las variables respuesta corresponden a los valores de $\mathrm{IC}_{50}$, expresado en ppm, y las variables explicativas corresponden al porcentaje (\%) de captación de los radicales libres. En el análisis de varianza de post-hoc de Tukey, las letras (A, B, C, D), corresponden al agrupamiento que se da como resultado de la similitud entre los datos del análisis de varianza.

\section{Resultados}

Los resultados de la evaluación de la capacidad antioxidante de los musgos B. subdisticha, $L$. viticulosoides y $P$. falcata, mediante los métodos aplicados de $\mathrm{DPPH}^{*}$ y $\mathrm{ABTS}^{*+}$, fueron.

Método de decoloración DPPH*: los datos correspondientes al porcentaje de captación del radical DPPH* para los extractos etanólicos de las tres especies mostraron los mejores valores de absorción respecto a los extractos de diclorometano (Tabla 1). En primer lugar, se encontró $L$. viticulosoides, con $71.20 \pm 0.114$ en una concentración de $40 \mathrm{mg} / \mathrm{L}$ y un máximo de absorción total del extracto de $81.87 \pm 0.136$ en una concentración de $200 \mathrm{mg} / \mathrm{L}$. Para B. subdisticha, se observaron $36.51 \pm 0.084$ en una concentración de 40 $\mathrm{mg} / \mathrm{L}$ y un máximo de absorción total del extracto de $68.25 \pm 0.142$ en una concentración de $200 \mathrm{mg} / \mathrm{L}$. Por último, siguió $P$. falcata, con $27.76 \pm 0.084$ en una concentración de $40 \mathrm{mg} / \mathrm{L}$ y un máximo de absorción total del extracto de $58.66 \pm 0.148$ en una concentración de $200 \mathrm{mg} / \mathrm{L}$ (Tabla 1).

Con los porcentajes de captación de radicales libres por los métodos de decoloración $\mathrm{DPPH}^{*}$ y ABTS $^{*+}$ (Tabla 1) se calculó la concentración media inhibitoria $\mathrm{IC}_{50}$ (Tabla 2).

Los extractos etanólicos de las tres especies presentaron valores de $\mathrm{IC}_{50}$ más bajos que los estándares, es decir, mostraron una mayor capacidad antioxidante. Leptodontium viticulosoides presentó los mejores valores 81.61, llegando a superar al patrón rutina, seguido por $B$. subdisticha (92.98) y por último $P$. falcata (141.66) (Figura 1). 
Téllez-Rocha et. al

Tabla 1. Porcentaje de captación de radicales libres por los métodos de decoloración DPPH* y ABTS*+

\begin{tabular}{|c|c|c|c|c|c|c|}
\hline \multicolumn{7}{|c|}{ DPPH $^{*}$} \\
\hline \multirow{2}{*}{ mg/L meOH } & \multicolumn{2}{|c|}{ L. viticulosoides } & \multicolumn{2}{|c|}{ B. subdisticha } & \multicolumn{2}{|c|}{ P. falcata } \\
\hline & Ex. EtOH & Ex. $\mathbf{C H}_{2} \mathrm{Cl}_{2}$ & Ex. EtOH & Ex. $\mathrm{CH}_{2} \mathrm{Cl}_{2}$ & Ex. EtOH & Ex. $\mathbf{C H}_{2} \mathrm{Cl}_{2}$ \\
\hline 40 & $71.20 \pm 0.114$ & $34.83 \pm 0.118$ & $36.51 \pm 0.084$ & $33.37 \pm 0.106$ & $27.76 \pm 0.084$ & $19.59 \pm 0.885$ \\
\hline 60 & $72.74 \pm 0.134$ & $35.96 \pm 0.115$ & $38.77 \pm 0.082$ & $35.98 \pm 0.115$ & $36.00 \pm 0.091$ & $27.00 \pm 0.110$ \\
\hline 80 & $73.69 \pm 0.126$ & $36.77 \pm 0.121$ & $43.04 \pm 0.091$ & $37.51 \pm 0.115$ & $40.41 \pm 0.107$ & $30.88 \pm 0.086$ \\
\hline 100 & $74.64 \pm 0.129$ & $38.72 \pm 0.128$ & $51.08 \pm 0.107$ & $38.15 \pm 0.112$ & $42.47 \pm 0.114$ & $33.10 \pm 0.087$ \\
\hline 120 & $75.23 \pm 0.127$ & $40.78 \pm 0.132$ & $53.09 \pm 0.111$ & $39.04 \pm 0.118$ & $44.67 \pm 0.123$ & $34.55 \pm 0.097$ \\
\hline 140 & $76.65 \pm 0.130$ & $43.98 \pm 0.138$ & $59.63 \pm 0.125$ & $40.00 \pm 0.121$ & $49.92 \pm 0.134$ & $36.84 \pm 0.099$ \\
\hline 160 & $78.90 \pm 0.133$ & $45.42 \pm 0.142$ & $61.64 \pm 0.128$ & $42.67 \pm 0.128$ & $51.27 \pm 0.134$ & $38.98 \pm 0.104$ \\
\hline 180 & $79.85 \pm 0.136$ & $46.99 \pm 0.146$ & $64.74 \pm 0.135$ & $43.05 \pm 0.128$ & $54.19 \pm 0.139$ & $42.10 \pm 0.111$ \\
\hline 200 & $81.87 \pm 0.136$ & $50.68 \pm 0.153$ & $68.25 \pm 0.142$ & $46.62 \pm 0.135$ & $58.66 \pm 0.148$ & $46.74 \pm 0.125$ \\
\hline \multicolumn{7}{|c|}{$\mathbf{A B T S}^{*+}$} \\
\hline \multirow{2}{*}{ mg/L meOH } & \multicolumn{2}{|c|}{ L. viticulosoides } & \multicolumn{2}{|c|}{ B. subdisticha } & \multicolumn{2}{|c|}{ P. falcata } \\
\hline & Ex. EtOH & Ex. $\mathrm{CH}_{2} \mathrm{Cl}_{2}$ & Ex. EtOH & Ex. $\mathrm{CH}_{2} \mathrm{Cl}_{2}$ & Ex. EtOH & Ex. $\mathrm{CH}_{2} \mathrm{Cl}_{2}$ \\
\hline 40 & $79.32 \pm 0.130$ & $37.43 \pm 0.080$ & $31.98 \pm 0.071$ & $27.76 \pm 0.062$ & $44.91 \pm 0.109$ & $13.68 \pm 0.052$ \\
\hline 60 & $86.25 \pm 0.146$ & $39.69 \pm 0.082$ & $48.16 \pm 0.105$ & $30.71 \pm 0.069$ & $50.29 \pm 0.117$ & $29.04 \pm 0.060$ \\
\hline 80 & $89.61 \pm 0.157$ & $41.14 \pm 0.082$ & $54.04 \pm 0.122$ & $31.69 \pm 0.073$ & $53.81 \pm 0.132$ & $33.05 \pm 0.070$ \\
\hline 100 & $91.03 \pm 0.162$ & $45.97 \pm 0.096$ & $59.38 \pm 0.137$ & $34.79 \pm 0.080$ & $57.93 \pm 0.128$ & $34.64 \pm 0.075$ \\
\hline 120 & $91.54 \pm 0.165$ & $47.74 \pm 0.099$ & $62.67 \pm 0.145$ & $37.06 \pm 0.086$ & $60.92 \pm 0.148$ & $37.31 \pm 0.080$ \\
\hline 140 & $92.26 \pm 0.172$ & $50.96 \pm 0.106$ & $70.38 \pm 0.162$ & $41.60 \pm 0.095$ & $66.09 \pm 0.162$ & $41.48 \pm 0.087$ \\
\hline 160 & $93.17 \pm 0.174$ & $52.57 \pm 0.107$ & $74.04 \pm 0.172$ & $45.99 \pm 0.106$ & $73.20 \pm 0.177$ & $45.15 \pm 0.091$ \\
\hline 180 & $93.68 \pm 0.177$ & $53.46 \pm 0.113$ & $79.16 \pm 0.186$ & $48.18 \pm 0.110$ & $80.68 \pm 0.194$ & $46.66 \pm 0.100$ \\
\hline 200 & $94.09 \pm 0.179$ & $54.10 \pm 0.113$ & $83.28 \pm 0.200$ & $53.25 \pm 0.121$ & $84.95 \pm 0.204$ & $47.16 \pm 0.101$ \\
\hline
\end{tabular}

Tabla 2. IC $_{50}$ y Actividad Antioxidante Relativa (\% ARR) por métodos $\mathrm{DPPH}^{*}$ y ABTS*+

\begin{tabular}{|c|c|c|c|c|c|c|c|c|}
\hline \multirow[b]{2}{*}{ Musgos } & \multicolumn{4}{|c|}{ DPPH $^{*}$} & \multicolumn{4}{|c|}{ ABTS $^{*+}$} \\
\hline & Ex. & $\mathrm{IC}_{50} *$ & AAR ascórbico & AAR rutina & $\mathrm{IC}_{50} *$ & AAR ascórbico & AAR rutina & AAR trolox \\
\hline \multirow[t]{2}{*}{ L. viticulosoides } & Ex. EtOH & 1.61 & 3.06 & 0.17 & 0.89 & 1.75 & 0.13 & 1.09 \\
\hline & Ex. $\mathrm{CH}_{2} \mathrm{Cl}_{2}$ & 257.63 & 490.43 & 28.00 & 138.71 & 273.32 & 20.01 & 170.09 \\
\hline \multirow[t]{2}{*}{ B. subdisticha } & Ex. EtOH & 92.98 & 177.00 & 10.11 & 70.63 & 139.17 & 10.19 & 86.60 \\
\hline & Ex. $\mathrm{CH}_{2} \mathrm{Cl}_{2}$ & 461.02 & 877.62 & 50.10 & 219.58 & 432.66 & 31.68 & 269.24 \\
\hline \multirow[t]{5}{*}{ P. falcata } & Ex. EtOH & 141.66 & 269.67 & 15.40 & 61.01 & 120.22 & 8.80 & 74.81 \\
\hline & Ex. $\mathrm{CH}_{2} \mathrm{Cl}_{2}$ & 305.47 & 581.50 & 33.20 & 214.80 & 423.25 & 30.99 & 263.39 \\
\hline & Ácido ascórbico & 0.53 & 1.00 & 0.06 & 0.51 & 1.00 & 0.07 & 0.62 \\
\hline & Rutina & 9.20 & 17.52 & 1.00 & 6.93 & 13.66 & 1.00 & 8.50 \\
\hline & Trolox & & & & 0.82 & 1.61 & 0.12 & 1.00 \\
\hline
\end{tabular}

Nota: *Concentración inhibitoria $50\left(\mathrm{IC}_{50}\right)$ en $\mathrm{mg} / \mathrm{L}$ de $\mathrm{MeOH}$.

La actividad antioxidante relativa (\% ARR) del extracto etanólico de L. viticulosoides, con respecto al ácido ascórbico, fue de 3.06 y 0.17 con relación a la rutina; el de $B$. subdisticha fue de 177.00 y 10.11 , y el de P. falcata de 269.67 y 15.40. Los extractos etanólicos presentaron mayor actividad antioxidante, encontrándose como mejor extracto el de L. viticulosoides. 

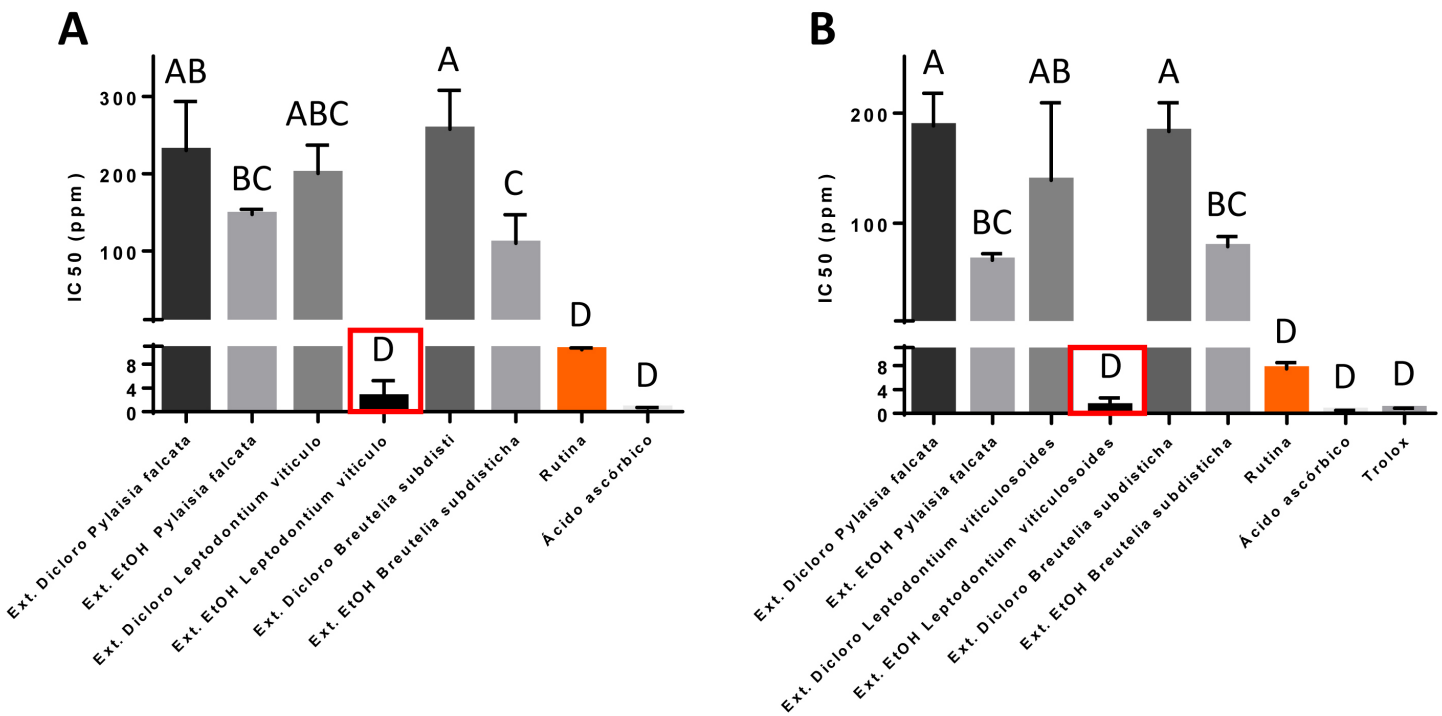

Figura 1. Valores de la $\mathrm{IC}_{50}$ para los diferentes extractos de las especies ensayadas y los controles positivos (ácido ascórbico, rutina y trolox). A. DPPH*; B. ABTS ${ }^{*+}$. Las letras más pequeñas de A, B, C, D indican los resultados de la comparación post-hoc de Tukey (nivel de confianza de 95\%; Tablas y Figuras Suplementarias S3, S4, S5, S6). Se resalta en rojo el extracto con mayor capacidad antioxidante (menor valor de la $\mathrm{IC}_{50}$ ) el extracto etanólico de L. viticulosoides, el cual mostró capacidad antioxidante sin diferencias significativas con los controles positivos empleados (ANOVA a una vía, post-hoc de Tukey).

Método de decoloración del radical ABTS ${ }^{*+}:$ los datos correspondientes al porcentaje de captación del radical $\mathrm{ABTS}^{*+}$ para los extractos etanólicos de las tres especies mostraron los mejores valores de absorción respecto a los extractos de diclorometano. En primer lugar, se encontró $L$. viticulosoides, con $79.32 \pm 0.130$ en una concentración de $40 \mathrm{mg} / \mathrm{L}$ y un máximo de absorción total del extracto de $94.09 \pm 0.179$ en una concentración de $200 \mathrm{mg} / \mathrm{L}$. Para P. falcata, se observaron $44.91 \pm 0.109$ en una concentración de $40 \mathrm{mg} / \mathrm{L}$ y un máximo de absorción total del extracto de $84.95 \pm 0.204$. Por último B. subdisticha, con $31.98 \pm 0.071$ en una concentración de $40 \mathrm{mg} / \mathrm{L}$ y un máximo de absorción total del extracto de $83.28 \pm 0.200$ (Tabla 1). Con estos porcentajes de absorción de radicales libres se calculó la $\mathrm{IC}_{50}$ (Tabla 2).

Igual como con el método anterior, cada uno de los extractos etanólicos de las tres especies presentaron los valores de $\mathrm{IC}_{50}$ más bajos que los estándares, exhibiendo una mayor capacidad antioxidante. Nuevamente L. viticulosoides presentó los mejores valores (0.89), llegando a superar al patrón rutina, seguido por $P$. falcata 61.01 y $B$. subdisticha (70.63).
La actividad antioxidante relativa (\% ARR) del extracto etanólico de L. viticulosoides, con respecto al ácido ascórbico, fue de 1.75 con relación a la rutina 0.13 y 1.09 respecto a trolox. Para $P$. falcata, los valores fueron de 120.22, 8.80 y 74.81, respectivamente, mientras que para $B$. subdisticha fueron de 139.17, 10.19 y 86.60. Como en el método anterior, los extractos etanólicos fueron los que presentaron mayor actividad antioxidante, encontrándose como mejor extracto el de $L$. viticulosoides.

\section{Discusión}

En este estudio se reporta por primera vez la actividad antioxidante para los musgos Breutelia subdisticha, Leptodontium viticulosoides y Pylaisia falcata, especies terrestres comunes en las zonas andinas de Colombia y con amplia distribución al menos en el Neotrópico. Con este trabajo, también se logró la comparación directa entre diferentes grupos filogenéticos (Bartramiales, Pottiales e Hypnales) [13, 14, 87, 88, 89], diferentes métodos de extracción $\left(\mathrm{CH}_{2} \mathrm{Cl}_{2}\right.$ y EtOH) y diferentes métodos de medición de la actividad antioxidante (DPPH*, ABTS $^{*+}$ ). Esto permite conclusiones sobre posibles 
relaciones de la actividad antioxidante con la filogenia y los factores asociados (morfología, ecología) y, a partir de los métodos de extracción y medición de actividad antioxidante, sobre los posibles metabolitos secundarios que pueden ser involucrados en la actividad antioxidante. Al comparar nuestros resultados con estudios previos con otras especies de musgos que usaron los mismos métodos, se observa algunos patrones (Tabla 3). Primero, estudios de la actividad antioxidante en musgos usando los métodos $\mathrm{DPPH}^{*}$ y $\mathrm{ABTS}^{*+}$ hasta ahora solo se han hecho en Colombia [74,75; este trabajo], India [90, 92], Indonesia [91] y con especies originando de la Antártida [52, 57]. Segundo, hay pocos géneros para los cuales se investigaron más de una especie, y en ningún caso más de dos (Breutelia, Leptodontium, Sphagnum, Thuidium), y solo para dos familias se investigaron más de un género: Leucobryaceae (Campylopus, Leucobryum) y Pottiaceae (Barbula, Leptodontium). Para dos de los tres géneros considerados en nuestro estudio, Breutelia y Leptodontium, existe datos para otras especies, B. chrysea y L. luteum (para Ex.EtOH y $\mathrm{DPPH}^{*}$ ), ambas estudiadas también en Colombia [74, 75]. Mientras los resultados entre las dos especies de Breutelia son comparables ( $\mathrm{IC}_{50}$ entre 90 y 160), teniendo $B$. subdisticha una actividad antioxidante ligeramente más alta que $B$. chrysea, se encontraron diferencias notables entre $L$. luteum y L. viticulosoides, el $\mathrm{IC}_{50}$ del último siendo casi dos órdenes de magnitud más baja (Tabla 3). Entre las dos especies de Sphagnum estudios en otros trabajos $[74,75]$ no se encontraron diferencias notables, mientras que para las dos especies de Thuidium, también incluido en otros estudios [75, 92], no hay datos directamente comparables. Con respeto a L. viticulosoides es notable que posee una mayor actividad antioxidante a partir del extracto etanólico que todas las demás especies investigadas, incluso Barbula javanica Dozy \& Molk., una especie de otro género de la misma familia [90]. En el único otro caso de dos especies estudiados de diferentes géneros de la misma familia, Campylopus schmidii (Müll. Hal.) A. Jaeger y Leucobryum aduncum Dozy $\&$ Molk. (Leucobryaceae), los datos disponibles con base en los extractos metanólicos indican un nivel bajo de actividad antioxidante en ambos casos [91].
Estos resultados muestran que las relaciones filogenéticas no necesariamente permiten predecir el nivel de actividad antioxidante, ya que puede variar sustancialmente entre especies del mismo género (Leptodontium) y entre géneros de la misma familia (Barbula, Leptodontium), aunque en otros casos (especies de Breutelia y géneros de Leucobryaceae) es comparable. Alternativamente, se podría considerar factores ecológicos y exposición a contaminación. Por ejemplo, los ejemplares de Breutelia subdisticha utilizados en nuestro estudio se encontraron en un parque que hace parte de la ciudad de Bogotá, mientras que los ejemplares de Breutelia chrysea (Müll. Hal.) A. Jaeger fueron recolectados en áreas rurales del departamento de Antioquia [74, 75].

Al comparar todas las especies investigadas (Tabla 3), se evidencia que la variación en la actividad antioxidante según especie oscila entre más de tres órdenes de magnitud $\left(\mathrm{IC}_{50}\right.$ de 1.61 hasta $>2000$ ). Después de Leptodontium viticulosoides, siguen en forma ordenada de mayor a menor grado de actividad antioxidante las siguientes especies: Thuidium tamariscellum (Müll. Hal.) Bosch \& Sande Lac. (Thuidiaceae, Hypnales) [92], Polytrichastrum alpinum (Hedw.) G.L. Sm. (Polytrichaceae, Polytrichales), [57], Leptodontium luteum (Pottiaceae, Pottiales) [74], Breutelia subdisticha (Bartramiaceae, Bartramiales) [este trabajo], Barbula javanica Dozy \& Molk. (Pottiaceae, Pottiales) [90], Dicranum frigidum (Dicranaceae, Dicranales), Sphagnum recurvum (Sphagnaceae, Sphagnales) y Thuidium peruvianum (Thuidiaceae, Hypnales) [75], Sphagnum sp. (Sphagnaceae, Sphagnales) [74], Pylaisia falcata (Hypnaceae, Hypnales) [este trabajo], Breutelia chrysea (Bartramiaceae, Bartramiales) [74], Sanionia uncinata (Hedw.) Loeske (Scorpidiaceae, Hypnales) [52], Leucobryum aduncum (Leucobryaceae, Dicranales) y Campylopus schmidii (Leucobryaceae, Dicranales) [91]. Como mencionamos anteriormente, el patrón observado parece ser independiente de la relación filogenética entre los géneros y las especies [14, 88, 89]. Sin embargo, se reconoce que miembros de las familias Polytrichaceae y Pottiaceae presentan niveles de actividad antioxidante mediana a alta, mientras que en miembros de la familia Leucobryaceae es más 
Tabla 3. Análisis de la actividad antioxidante por métodos $\mathrm{DPPH}^{*}$ y $\mathrm{ABTS}^{*+}$ según diferentes estudios. Las especies están en órden alfabético

\begin{tabular}{|c|c|c|c|c|c|c|c|c|c|}
\hline \multirow{3}{*}{ Musgos } & \multicolumn{9}{|c|}{$\mathrm{IC}_{50}(\mathrm{mg} / \mathrm{L})$} \\
\hline & \multicolumn{4}{|c|}{ DPPH $^{*}$} & \multicolumn{4}{|c|}{ ABTS $^{*+}$} & \multirow{2}{*}{$\begin{array}{l}\text { País y } \\
\text { referencia }\end{array}$} \\
\hline & Ex. МeOH & Ex.EtOH & Ex. $\mathrm{CH}_{2} \mathrm{Cl}_{2}$ & Ex. $\mathrm{CHCl}_{3}$ & Ex. МeOH & Ex.EtOH & Ex. $\mathbf{C H}_{2} \mathbf{C l}_{2}$ & Ex. $\mathrm{CHCl}_{3}$ & \\
\hline Barbula javanica & - & $100 \pm 1.12$ & - & - & - & - & - & - & India [90] \\
\hline Breutelia chrysea & - & $>100-158.0$ & - & - & - & - & - & - & $\begin{array}{l}\text { Colombia [74, } \\
75]\end{array}$ \\
\hline $\begin{array}{l}\text { Breutelia } \\
\text { subdisticha }\end{array}$ & - & 92.98 & 461.02 & - & - & 139.17 & 432.66 & - & $\begin{array}{l}\text { Colombia [este } \\
\text { trabajo] }\end{array}$ \\
\hline $\begin{array}{l}\text { Campylopus } \\
\text { schmidii }\end{array}$ & $>2000$ & - & - & - & - & - & - & - & Indonesia [91] \\
\hline $\begin{array}{l}\text { Dicranum } \\
\text { frigidum }\end{array}$ & - & $>100$ & - & - & - & 256.1 & - & - & $\begin{array}{l}\text { Colombia [74, } \\
75]\end{array}$ \\
\hline $\begin{array}{l}\text { Leptodontium } \\
\text { luteum }\end{array}$ & - & $60.6->100$ & - & - & - & - & - & - & $\begin{array}{l}\text { Colombia [74, } \\
75]\end{array}$ \\
\hline $\begin{array}{l}\text { Leptodontium } \\
\text { viticulosoides }\end{array}$ & - & 1.61 & 257.63 & - & - & 0.89 & 138.71 & - & $\begin{array}{l}\text { Colombia [este } \\
\text { trabajo] }\end{array}$ \\
\hline $\begin{array}{l}\text { Leucobryum } \\
\text { aduncum }\end{array}$ & $1329,02 \pm 7,8$ & - & - & - & - & - & - & - & Indonesia [91] \\
\hline $\begin{array}{l}\text { Polytrichastrum } \\
\text { alpinum }\end{array}$ & $56.8 \pm 0.8$ & - & - & - & $103.98 \pm 9.8$ & - & - & - & Antártida [57] \\
\hline Pylaisia falcata & - & 141.66 & 305.47 & - & - & 61.01 & 214.80 & - & $\begin{array}{l}\text { Colombia [este } \\
\text { trabajo] }\end{array}$ \\
\hline $\begin{array}{l}\text { Sanionia } \\
\text { uncinata }\end{array}$ & - & $356 \pm 26.8$ & & - & - & $181.3 \pm 12.2$ & - & - & Antártida [52] \\
\hline $\begin{array}{l}\text { Sphagnum } \\
\text { recurvum }\end{array}$ & - & $>100$ & - & - & - & - & - & - & Colombia [75] \\
\hline Sphagnum sp. & - & $>100-132.4$ & & - & - & - & - & - & $\begin{array}{l}\text { Colombia [74, } \\
75]\end{array}$ \\
\hline $\begin{array}{l}\text { Thuidium } \\
\text { peruvianum }\end{array}$ & - & $>100$ & - & - & - & - & - & - & Colombia [75] \\
\hline $\begin{array}{l}\text { Thuidium } \\
\text { tamariscellum }\end{array}$ & - & - & - & - & - & - & 16 & 18.5 & India [92] \\
\hline
\end{tabular}

baja. Notablemente, miembros de las familias Polytrichaceae y Pottiaceae generalmente viven en zonas abiertas, expuestas directamente a los rayos solares, mientras que especies de la familia Leucobryaceae prefieren suelos y maderas en descomposición en bosques húmedos tropicales a bosques andinos [16]. Esto suele soportar la hipótesis expuesta anteriormente que la ecología, más que la filogenia, determina el potencial antioxidante, a nivel de especie, género o familia. De esta forma nos podría llevar a predecir que especies, géneros y familias de musgos presentes en áreas urbanas o con mayor exposición a rayos solares y altos niveles de contaminación podrían ser los más prometedores términos de actividad antioxidante. Sin embargo, es importante notar que las dos especies estudiadas de la Antártida, Polytrichastrum alpinum y Sanonia uncinata [52, 57], defendiblemente occurriendo en un habitat extremo, demuestran niveles de actividad antioxidante variable (Tabla 3).

Los patrones con relación al ensayo ABTS $^{*+}$ en su mayoría son comparables con los de $\mathrm{DPPH}^{*}$. Igualmente, L. viticulosoides presentó la mejor actividad antioxidante, seguido por Thuidium tamariscellum [92], Sphagnum sp. [74], Pyalisia falcata, Polytrichastrum alpinum [57], Breutelia subdisticha, Sanonia uncinata [52] y Dicranum frigidum [74]. Nuevamente encontramos que, en musgos expuestos directamente a los rayos solares, L. viticulosoides y T. tamariscellum [92], 
los aspectos ecológicos podrían ser un factor clave para el reconocimiento de especies con altas niveles actividad antioxidante. Como fue encontrado para $\mathrm{DPPH}^{*}$, igualmente para $\mathrm{ABTS}^{*+}$, la especie Sanionia uncinata, aunque basado en material de la Antártida, presenta menor actividad antioxidante [52], lo que indica que podría haber otros factores que determinan el potencial antioxidante en una especie dada. Sanonia uncinata es una especie de altas montañas y tierras frías ampliamente distribuida en el hemisferio norte. Se ha cuestionado su ocurrencia en el hemisferio sur, pero los autores del estudio [52] confirmaron su identificación mediante el marcador molecular del ITS, con el registro de GenBank de EU267027, el cual indica que $S$. uncinata en efecto es una especie cosmopolita, incluyendo como potencial sinónimo a S. georgicouncinata (Müll. Hal.) Ochyra \& Hedenäs, una especie descrita desde la Antártida. Aunque típica de tierras frías, S. uncinata crece en micrositios protegidos que se caracterizan por inversión local de temperatura, lo que podría explicar su bajo nivel de actividad antioxidante. Aparte de las diferencias entre grupos filogenéticos y taxones con diferente ecología, nuestro trabajo también confirma resultados de otros estudios que la actividad antioxidante varia bastante según método de extracción y de medida, es decir DPPH* y ABTS $^{*+}$. La actividad antioxidante, evaluada en este estudio como la concentración de extracto que reduce el $50 \%$ de $\mathrm{DPPH}^{*}$ y $\mathrm{ABTS}^{*+}$ (concentración inhibitoria 50; $\mathrm{IC}_{50}$ ), se clasifica de acuerdo a Makajanma et al., 2020 [91] en cinco categorías: muy fuerte $(<$ $50 \mathrm{mg} / \mathrm{L})$, fuerte $(50-100 \mathrm{mg} / \mathrm{L})$, moderada (101$250 \mathrm{mg} / \mathrm{L}$ ), débil (251-500 mg/L), y muy débil (> $500 \mathrm{mg} / \mathrm{L}$ ). Por ende, según los valores obtenidos para $\mathrm{DPPH}^{*}$ mediante el extracto diclorometano $\left(\mathrm{CH}_{2} \mathrm{Cl}_{2}\right)$, B. subdisticha presentó una actividad moderada, mientras que $L$. viticulosoides y $P$. falcata presentaron una actividad débil. Por el contrario, según los valores obtenidos mediante el extracto etanólico (EtOH), L. viticulosoides mostró una actividad muy fuerte, $B$. subdisticha una actividad fuerte y $P$. falcata una actividad moderada. Una variación semejante se encontró con los valores obtenidos para $\mathrm{ABTS}^{*+}$. Con el extracto diclorometano $\left(\mathrm{CH}_{2} \mathrm{Cl}_{2}\right)$, L. viticulosoides y $P$. falcata presentaron una actividad moderada y $B$. subdisticha una actividad débil, mientras que con el extracto etanólico (EtOH), L. viticulosoides mostró una actividad muy fuerte, $P$. falcata una actividad fuerte y $B$. subdisticha una actividad moderada. Es preciso señalar que el método $\mathrm{DPPH}^{*}$ es más selectivo que el método ABTS ${ }^{*+}$ y se ha reportado que en el caso de los polifenoles la capacidad antioxidante cambia significativamente entre un método y otro [74]. Por lo tanto, las diferencias observadas entre los diferentes métodos podrían causarse por diferentes afinidades de los métodos a diferentes clases de sustancias involucradas en la actividad antioxidante. De ser así, el potencial antioxidante de una especie no se calcularía como promedio de los resultados de los diferentes métodos sino se indicaría por el valor que corresponde a la categoría más fuerte, la cual permite conclusiones sobre los metabolitos secundarios involucrados en el mecanismo antioxidante. Nuestro trabajo es el primero para musgos donde se permite comparar la sensibilidad de métodos de extracción (etanólicos versus clorofórmicos), claramente indicando que el método etanólico es más efectivo para sustancias con potencial antioxidante.

En cuanto a los métodos $\mathrm{DPPH}^{*}$ y $\mathrm{ABTS}^{*+}$, las especies estudiadas muestran patrones diferentes. Categorías de potencial antioxidante más fuertes para $\mathrm{DPPH}^{*}$ en comparación con $\mathrm{ABTS}^{*+}$ se encontraron para Dicranum frigidum [74, 75] y Polytrichastrum alpinum [57], mientras que el patrón invertido fue encontrado en Leptodontium visiculosoides, Pylaisia falcata [ambas este trabajo], Sanionia uncinata [52] y Sphagnum sp. [74, 75]; para Breutelia subdisticha [este trabajo] y Thuidium tamariscellum [92] no se encontraron diferencias sustanciales (Tabla 3). Notablemente, estas diferencias no se relacionan con la filogenia de estas especies [87, 88, 89].

Es importante notar que, tanto por el método $\mathrm{DPPH}^{*}$ como por el método ABTS ${ }^{*+}$, Leptodontium viticulosoides presentó la actividad antioxidante más fuerte en comparación con las demás especies de musgos, prácticamente un orden de magnitud mejor que la segunda especie, Thuidium tamarisellum (Tabla 3). De hecho, L. viticulosoides mostró valores que no se distinguen significativamente 
de los patrones (ácido ascórbico, rutina y trolox), todos saliendo en el grupo D de la prueba de ANOVA y la comparación post-hoc de Tukey. Este nivel del potencial antioxidante se podría considerar extraordinario, indicando que $L$. viticulosoides constituye una fuente natural potente e importante de capacidad antioxidante, pero es necesario confirmar con más estudios. Leptodontium visiculosoides es una especie común, con amplia distribución, siendo pantropical y extendiéndose a zonas subtropicales y parcialmente templadas en Norteamérica, Suráfrica y Asia. Su abundancia y su amplia distribución indican que es una especie exitosa en términos evolutivos y su alto potencial antioxidante podría ser uno de los factores explicando esta distribución.

Considerando que los extractos etanólicos poseen una alta polaridad, la observación que dan los mejores resultados en términos de actividad antioxidante se podría explicar por la probable presencia de polifenoles [74]. Dentro de los polifenoles, se hallan los flavonoides, los cuales presentan actividad antioxidante con posible aplicación farmacológica [93]. Infortunadamente, para Breutelia subdisticha (Bartramiaceae) y Pylaisia falcata (Hypnaceae) no se encontraron datos sobre sus metabolitos secundarios, aunque en otras especies de Bartramiaceae se han detectado flavonoides (biflavonoides, triflavonoides) [94, 95, 96, 99] y para otras especies de Hypnaceae se han reportado terpenoides (monoterpenoides, diterpenoides, sesquiterpenoides) [93, 97, 102-104] y flavonoides (biflavonoides) [98, 99, 100]. Para Leptodontium viticulosoides (Pottiaceae), un estudio registró la presencia de terpenoides (sesquiterpenoides) [105], mientras estudios enfocados en otros géneros de la misma familia han detectado terpenoides y flavonoides (biflavonoides) [99, 101]. Estos metabolitos secundarios actúan como compuestos bioactivos [39], catalogándose principalmente como antioxidantes, es decir, como moléculas con actividad redox, dinámicamente involucradas en el mantenimiento del equilibrio redox en la célula. Además, ejercen un efecto inhibidor sobre el crecimiento y desarrollo de patógenos [61, 106].
Los terpenoides y flavonoides son los antioxidantes mejor conocidos en el metabolismo secundario de las briofitas, mostrando un alto nivel de variabilidad en términos de abundancia relativa dentro de las diferentes especies [92, 106]. Los flavonoides son potentes captadores de radicales libres y pueden ser utilizados en terapias contra enfermedades asociados a estos radicales [107]. Lo mismo aplica a los terpenoides que, además de poseer la capacidad de prevenir la progresión de células tumorales, pueden modular el estado redox y actuar sobre procesos celulares como la proliferación celular, diferenciación, inflamación, apoptosis y angiogénesis [100]. Al mismo tiempo, se ha encontrado que la vía biosintética de los polifenoles en los musgos se activa tras el ataque de diferentes patógenos, lo que indica el papel importante de estos metabolitos secundarios en la protección, defensa y acción enzimática de estos organismos [106, 108]. Notablemente, el contenido de dichos compuestos fenólicos depende de varios factores como el tipo de sustrato, altitud, clima, hábitat, la condición ambiental o el genotipo [100], lo que soporta la hipótesis anteriormente mencionada de la relación entre el potencial antioxidante de las especies de musgos y su ecología. De hecho, se ha reportado que tanto flavonoides como terpenoides son los componentes principales de la tolerancia al estrés biótico y abiótico [109], incluyendo protección contra la luz, mediación con respecto a las interacciones bióticas y patógenas y cierta tolerancia a bajas temperaturas y la desecación [110-114], Por ejemplo, los musgos pueden sobrevivir períodos prolongados de estrés por frío mediante la producción incrementada de ciertos terpenoides [110]. Estas adaptaciones bioquímicas se ven acompañadas por adaptaciones morfo-anatómicas, particularmente con respecto a la tolerancia a la desecación. Aunque los musgos son poiquilohídricos, para solucionar el problema funcional de conciliar la conducción externa con las necesidades de intercambio de gases, poseen hojas papilosas (Pottiaceae) u hojas cóncavas que permiten tanto la conducción capilar externa como el intercambio de gas libre, o hojas cerosas repelentes al agua (Bartramiaceae) que facilitan la conducción periférica [111]. 
Los musgos estudiados aquí poseen diferentes hábitos de crecimiento [88, 89]. Leptodontium viticulosoides y $B$. subdisticha son acrocárpicos mientras que $P$. falcata es pleurocárpico. Notablemente, esto tiene una relación estrecha con la actividad antioxidante que exponen, siendo más fuerte en las dos especies acrocárpicos a partir de los extractos etanólicos por el método $\mathrm{DPPH}^{*}$. Esto se podría explicar por la observación que los musgos acrocárpicos contienen más alta concentración de flavonoides que los pleurocárpicos [115]. Curiosamente, esos autores encontraron que el contenido total de flavonoides de los briófitos que crecen a niveles de luz más bajos es generalmente más alto que las que crecen a pleno sol [115] lo que suele contradecir la hipótesis que el potencial antioxidante incrementa con la exposición solar. Sin embargo, el trabajo mencionado no aplica un análisis multivariado de los datos, así que no se puede excluir efectos de interacción entre los diferentes parámetros ambientales, tales como luz, hábitat, altitud y latitud [115]. Considerando que otros trabajos han señalado una relación entre el contenido total de flavonoides y factores ambientales como luz, hábitat, altitud y latitud [70], es evidente el potencial de estudios por adelante que podrían ayudar a resolver la importancia de estos factores.

\section{Conclusiones}

Nuestro estudio y la comparación con trabajos anteriores ha demostrado que la variación del potencial antioxidante en especies de musgos sigue un patrón complejo, dependiendo no solamente de parámetros como la ecología y factores como las relaciones filogenéticas, sino también de los métodos aplicados, tanto de extracción como medida de actividad antioxidante. Los datos disponibles hasta la fecha indican que la ecología juega un papel más importante que la filogenia. Los resultados sugieren que musgos que viven en zonas abiertas, expuestas directamente a los rayos solares, tales como áreas urbanas, por ejemplo, frecuente en especies de la familia Pottiaceae, podrían ser elementos prometedores de estudios sobre su posible actividad antioxidante. Sin embargo, la evidencia es parcialmente contradictoria y además es difícil desenredar las correlaciones que se dan entre la filogenia, morfología y ecología de las especies.

Nuestro estudio es el primero que suele indicar que la extracción etanólica es más efectiva que la extracción con diclorometano, pero hasta ahora no existen estudios que han comparado los cuatro métodos de extracción, incluyendo también la metanólica y la clorofórmica. Por lo tanto, no es posible poner los resultados de estudios que usaron solamente la extracción metanólica en contexto.

A partir de estos resultados, se recomienda seguir con estudios más profundos en cuatro direcciones: primero, una mayor comparación de muchas especies de musgos usando una amplia gama de métodos de extracción y poner los resultados en un contexto multivariado de parámetros ambientales, al mismo tiempo considerando las relaciones filogenéticas de las especies estudiadas; segundo, estudios sobre la composición de metabolitos secundarios de una amplia gama de especies; tercero, el enfoque en especies "modelo" donde se analiza la misma especie encontrada bajo diferentes condiciones, para evaluar el nivel de variación intraespecífica; y cuarto, hacer ensayos de tipo antitumoral para ver el potencial clínico de estos patrones.

Para las tres últimas direcciones, Leptodontium visiculosoides podría ser una especie candidata promisoria, considerando el alto potencial antioxidante encontrado para esta especie en nuestro trabajo, obteniendo valores de $\mathrm{IC}_{50}$ comparables a los patrones utilizados (ácido ascórbico, rutina y trolox). En consecuencia, se sugiere que este musgo $L$. viticulosoides sea objeto de investigaciones posteriores detalladas, realizándole aislamiento, purificación, y caracterización de los compuestos antioxidantes bioactivos y buscando aplicaciones como agentes terapéuticos, anticancerígenos y antitumorales.

\section{Material suplementario}

Figuras y Tablas suplementarias (Material Suplementario 1) y Datos originales (Material Suplementario 2) están disponibles como material suplementario. 


\section{Agradecimientos}

Los autores expresamos nuestro agradecimiento a la Fundación Universitaria Juan N. Corpas, a la Universidad Distrital Francisco José de Caldas, al Parque Ecológico Distrital Entrenubes, al Herbario José Jerónimo Triana (HJJT), al curador especialista en briófitos, Manuel David Cortés y a los jurados revisores porque sus comentarios, correcciones y sugerencias permitieron enriquecer este documento.

\section{Referencias}

[1] L. Castro, B.A. Freeman, "Reactive Oxygen Species in Human Health and Disease. Science", Nutrition, vol. 17, no. 2, pp. 161-165, 1954. DOI: 10.1016/s0899-9007(00)00570-0

[2] I.S. Young, J.V. Woodside, "Antioxidants in health and disease", Journal of Clinical Pathology, vol. 54, pp. 176-186, 2001. DOI: 10.1136/jcp.54.3.176

[3] B. Halliwell, J.M.C. Gutteridge, "Free Radicals in Biology and Medicine". United Kingdom: Oxford University Press, 2007.

[4] R. Mittler, "Oxidative stress, antioxidants and stress tolerance", Trends in Plant Science, vol. 7, no. 9, pp. 405-410, 2002. DOI: 10.1016/s1360-1385(02)02312-9

[5] A. Thomas-Schoemann, J. Alexandre, C. Mongaret, S. Azibi, A. Dauphin, F. Goldwasser, F. Lemare, "Prise d'antioxydants et d'autres thérapies complémentaires par les patients sous chimiothérapie antitumorale: étude prospective”, Bull Cancer, vol. 98, pp. 645653, 2011. DOI: 10.1684/bdc.2011.1375

[6] D. Robbins, Y. Zhao, "The Role of Manganese Superoxide Dismutase in Skin Cancer", Enzyme Research, pp. 1-7, 2011. DOI: $10.4061 / 2011 / 409295$

[7] A. Yadav, R. Kumari, A. Yadav, J.P. Mishra, S. Srivatva, S. Prabha, "Antioxidants and its functions in human body - A Review", Research in Environment and Life Sciences, vol. 9, no. 11, pp. 1328-1331, 2016.
[8] S.R. Gradstein, S.P. Churchill, N. SalazarAllen, "Guide to the Bryophytes of Tropical America", Editorial Board. New York: Memoirs of the New York Botanical Garden, 2001.

[9] A. Vanderpoorten, B. Goffinet, "Introduction to Bryophytes", Cambridge University Press, New York, 2009. DOI: 10.1017/CBO9780511626838

[10] M.C.F. Proctor, "Physiological ecology". In: Goffinet B, Shaw AJ Eds. Bryophyte biology, 2nd edition. Cambridge University Press, Cambridge, pp. 237-268, 2009. DOI: 10.1017/cbo9781139171304.009

[11] B. Estébanez-Pérez, I. Draper Díaz De Atauri, R. Medina-Bujalance, "Briófitos: Una aproximación a las plantas terrestres más sencillas", Memorias de la Real Sociedad Española de Historia Natural, vol. 2, no. 9, pp. 1-56, 2011.

[12] A.J. Shaw, P. Szövényi, B. Shaw, "Bryophyte Diversity and Evolution: Windows into the early evolution of lands plants", American Journal of Botany, vol. 98, no. 3, pp. 352-369, 2011. DOI: 10.3732/ajb.1000316

[13] C.J. Cox, B. Goffinet, N.J. Wickett, S.B. Boles, A.J. Shaw, "Moss diversity: A molecular phylogenetic analysis of genera", Phytotaxa, vol. 9, pp. 175-195, 2010. DOI: 10.11646/phytotaxa.9.1.10

[14] R. Bernal, S. Gradsteins, and M. Celis, "Catálogo de plantas y líquenes de Colombia", vol. I. Bogotá, Colmbia: Universidad Nacional de Colombia (Sede Bogotá). Facultad de Ciencias. Instituto de Ciencias Naturales, 2016.

[15] S. R. Gradstein, "Key to hornworts (Anthocerotophyta) of Colombia", Caldasia, vol. 40, 2, pp. 262-270, 2018. DOI: 10.15446/caldasia.v40n2.71750

[16] S.P. Churchill, E. Linares, "Prodromus Bryologiae Novo-Granatensis: Introducción a la Flora de Musgos de Colombia Parte I", Editora Guadalupe Ltda, Santa fé de Bogotá, pp. 490, 1995. 
[17] J.M. Glime, "Economic and Ethnic Uses of Bryophytes", In: Flora of North America Editorial Committee, eds. 1993. Flora of North America North of Mexico. 15+ vols. New York \& Oxford, vol. 27, pp. 14-41, 2007.

[18] [18] S. Flowers, "Ethnobryology of the Gosuite Indians of Utah", The Bryologist, vol. 60, no. 1, pp. 1-11, 1957. DOI: $10.2307 / 3240044$

[19] M.S. Sabovljeviić, A.D. Sabovljeviić, N.K. Ikram, A. Peramuna, H. Bae, H.T. Simonsen, "Bryophytes - an emerging source for herbal remedies and chemical production", Plant Genetic Resources: Characterization and Utilization, vol. 14, no. 4, pp. 314-327, 2016. DOI: $10.1017 /$ S1479262116000320

[20] O. Tonguç- Yayintaş, "Bryophytes as hidden treasure", Journal of Scientific Perspectives, vol. 2, no. 1, pp. 71-83, 2018. DOI: $10.26900 /$ jsp. 2018.07

[21] J.P. Frahm, "Recent Developments of Commercial Products from Bryophytes", The Bryologist, vol. 107, no. 3, pp. 277-283, 2004.

[22] G. Montenegro, M. Portaluppi, F.A. Salas, M.F. Díaz, "Biological properties of the Chilean native moss Sphagnum magellanicum", Biological Research, vol. 42, pp. 233-237, 2009. DOI: $10.4067 / \mathrm{s} 0716-97602009000200012$

[23] Ö. Ertürk, H. Sahin, E.Y. Ertürk, H.E. Hotaman, B. Koz, Ö. Özdemir, "The antimicrobial and antioxidant activities of extracts obtained from some moss species in Turkey", Herba Polonica, vol. 61, no. 4, pp. 52-65, 2015. DOI: 10.1515/hepo-2015-0031

[24] A. Dey, J. Nath De, "Antioxidative Potential of Bryophytes: Stress Tolerance and Commercial Perspectives: A Review", Phannacologia, vol. 3, no. 6, pp. 151-159, 2012. DOI: 10.5567/pharmacologia.2012.151.159

[25] A. Dey, A. Mukherjee, "Therapeutic potential of bryophytes and derived compounds against cancer", Journal of Acute Disease, vol. 4, no. 3, pp. 236-248. 2015. DOI: 10.1016/j.joad.2015.04.011
[26] D.K. Saxena, Harinder, "Uses of bryophytes". Resonance, vol. 9, no. 6, pp. 56-65, 2004. DOI: $10.1007 / \mathrm{bf} 02839221$

[27] Y. Asakawa, "Biologically active compounds from bryophytes". Pure and Applied Chemistry, vol. 79, no. 4, pp. 557-580, 2007. DOI: 10.1351/pac200779040557

[28] E.S.J. Harris, "Ethnobryology: traditional uses and folk classification of bryophytes", The Bryologist, vol. 111, no. 2, pp. 169-217, 2008.

[29] A. Alam, V. Shrama, K.K. Rawat, P.K. Verma, "Bryophytes - The Ignored Medicinal Plants", SMU Medical Journal, vol. 2, no. 1, pp. 299316, 2015.

[30] Y. Asakawa, A. Ludwiczuk, "Chemical Constituents of Bryophytes: Structures and Biological Activity", Journal of Natural Products, vol. 81, pp. 641-660, 2018. DOI: 10.1021/acs.jnatprod.6b01046

[31] M. Saxena, J. Saxena, R. Nema, D. Singh, A. Gupta, "Phytochemistry of Medicinal Plants", Journal of Pharmacognosy and Phytochemistry, vol. 1, no. 6, pp. 168-182, 2013.

[32] G.M. Greeshma, G.S. Manoj, K. Murugan, "Insight into pharmaceutical importance of bryophytes", Kongunadu Research Journal, vol. 4, no. 2, pp. 84-88, 2017. DOI: $10.26524 / \mathrm{krj} 208$

[33] Y. Asakawa, A. Ludwiczuk, "Bryophytes: Liverworts, Mosses, and Hornworts: Extraction and Isolation Procedures", Metabolomics Tools for Natural Product Discovery, pp. 1-20, 2013. DOI: 10.1007/978-1-62703-577-4_1

[34] Y. Asakawa, "Chemical Constituents of the Bryophytes", Progress in the Chemistry of Organic Natural Products, pp. 1-562, 1995. DOI: 10.1007/978-3-7091-6896-7_1

[35] H. Geiger, T. Seeger, H. Dietmar- Zinsmeister, J.P. Frahm, "The ocurrence of flavonoids in arthrodontous mosses- An account of the 
present knowledge", J. Hattori Bot. Lab., vol. 83, pp. 273-308, 1997.

[36] C. Suire, G. Bourgeois, T. Koponen, "Some chemical constituents of thirteen mosses from the traditional Mniaceae family", Journal of the Hattori Botanical Laboratory, vol. 89, pp. 233-246, 2000.

[37] Y. Asakawa, "Recent advances in phytochemistry of bryophytes- acetogenins, terpenoids and bis(bibenzyl)s from selected Japanese, Taiwanese, New Zealand, Argentinean and European liverworts", Phytochemistry, vol. 56, no. 3, pp. 297-312, 2001. DOI: 10.1016/s00319422(00)00454-4

[38] C.F. Xie, H.X. Lou, "Secondary Metabolites in Bryophytes: An Ecological Aspect", Chemistry \& Biodiversity, vol. 6, no. 3, pp. 303-312, 2009. DOI: 10.1002/cbdv.200700450

[39] Y. Asakawa, A. Ludwiczuk, F. Nagashima, "Phytochemical and biological studies of bryophytes", Phytochemistry, pp. 1-29, 2012. DOI: 10.1016/j.phytochem.2012.04.012

[40] Y. Asakawa, A. Ludwiczuk, F. Nagashima, "Chemical constituents of bryophytes: bioand chemical diversity, biological activity, and chemosystematics", Progress in the Chemistry of Organic Natural Products. Springer, vol. 95, pp. 1-796, 2013. DOI: 10.1007/978-3-70911084-3

[41] K. Peters, K. Gorzolka, H. Bruelheide, S. Neumann, "Seasonal variation of secondary metabolites in nine different bryophytes", Ecology and Evolution, vol. 8, pp. 9105-9117, 2018. DOI: $10.1002 /$ ece 3.4361

[42] Y. Saritas, M.M. Sonwa, H. Iznaguen, W.A. König, H. Muhle, R. Mues, "Volatile constituents in mosses (Musci)", Phytochemistry, vol. 57, no. 3, pp. 443-457, 2001. DOI: 10.1016/s0031-9422(01)00069-3

[43] Ivanova V, Kolarova M, Aleksieva K, Dornberger K, Haertl A, Moellmann U, et al., "Sanionins: Anti-Inflammatory and Antibacterial Agents with Weak Cytotoxicity from the
Antarctic Moss Sanionia georgico-uncinata", Preparative Biochemistry and Biotechnology, vol. 37, no. 4, pp. 343-352, 2007. DOI: $10.1080 / 10826060701593241$

[44] A.O. Adebiyi, A.A. Oyedeji, E.E. Chikwendu, O.A. Fatoke, "Phytochemical Screening of Two Tropical Moss Plants: Thidium gratum P. Beauv and Barbula indica Brid Grown in Southwestern Ecological Zone of Nigeria", American Journal of Analytical Chemistry, vol. 3, pp. 836-839, 2012. DOI: 10.4236/ajac.2012.312110

[45] J. Cuvertino- Santoni, Y. Asakawa, M. Nour, G. Montenegro, "Volatile Chemical Constituents of the Chilean Bryophytes", Natural Product Communications, vol. 12, no. 12, pp. 1929-1932, 2017. DOI: $10.1177 / 1934578 \times 1701201229$

[46] S. Kaur, S. Kapila, I.K. Maurya, "Phytochemical Analysis and Characterization of the Bioactive Compounds of Mnium cuspidatum by GC-MS and FTIR", International Journal of Life Sciences Research, vol. 7, no. 1, pp. 254-262, 2019.

[47] G. Zheng, C. Chang, "Ohioensins: novel benzonaphthoxanthenones from Polytrichum ohioense". Journal of Organic Chemistry, vol. 58, pp. 366-372, 1993. DOI: 10.1021/jo00054a019

[48] A. Basile, S. Giordano, J.A. López-Sáez, R.C. Cobianchi, "Antibacterial activity of pure flavonoids isolated from mosses", Phytochemistry, vol. 52, no. 8, pp. 1479-1482, 1999. DOI: 10.1016/s0031-9422(99)00286-1

[49] S. Ílhan, F. Savaroglu, F. Colak, C. Filik Iscen, F.Z. Erdemgil, "Antimicrobial Activity of Palustriella commutata (Hedw.) Ochyra Extracts (Bryophyta)", Turkish Journal of Biology, vol. 30, pp. 149-152, 2006.

[50] M. Veljić, A. Đurić, M. Soković, A. Ćirić, J. Glamočlija, D.P. Marin, "Antimicrobial activity of methanol extracts of fontinalis antipyretica, Hypnum cupressiforme, and 
Ctenidium molluscum", Archives of Biological Sciences, vol. 61, no. 2, pp. 225-229, 2009. DOI: 10.2298/ABS0901225V

[51] G. S. Deora, D. Suhalka, "Phytochemical Composition and Fungicidal Potential of Moss Philonotis revoluta against Spore Germination Process of Fungus Helminthosporium turcicum", IOSR Journal of Pharmacy and Biological Sciences, vol. 11, no. 6, pp. 38-43, 2016. DOI: $10.9790 / 3008-1106033843$

[52] H.D. Bhattarai, B. Paudel, H.S. Lee, Y.K. Lee, J.H. Yim, "Antioxidant activity of Sanionia uncinata, a polar moss species from King George Island, Antarctica", Phytotherapy Research, vol. 22, no. 12, pp. 1635-1639, 2008. DOI: $10.1002 /$ ptr.2538

[53] F.A. Karim, M. Suleiman, A. Rahmat, M.F. Abu- Bakar, "Phytochemicals, antioxidant and antiproliferative properties of five moss species from Sabah, Malaysia", International Journal of Pharmacy and Pharmaceutical Sciences, vol. 6, no. 10, pp. 292-297, 2014.

[54] X. Cheng, Y. Xiao, X. Wang, P. Wang, H. $\mathrm{Li}, \mathrm{H}$. Yan, et al., "Anti-tumor and proapoptotic activity of ethanolic extract and its various fractions from Polytrichum commune L.ex Hedw in L1210 cells", Journal of Ethnopharmacology, vol. 143, no. 1, pp. 4956, 2012. DOI: 10.1016/j.jep.2012.05.054

[55] V. Chobot, L. Kubicová, S. Nabbout, L. Jahodár, J. Vytlačilová, "Antioxidant and free radical scavenging activities of five moss species", Fitoterapia, vol. 77 no. 7-8, pp. 598600, 2006. DOI: 10.1016/j.fitote.2006.06.010

[56] V. Chobot, L. Kubicova, S. Nabbout, Jahodár, F. Hadacek, "Evaluation of Antioxidant Activity of Some Common Mosses", Zeitschrift für Naturforschung, vol. 63c, pp. 476-482, 2008. DOI: 10.1515/znc-2008-7-802

[57] H.D. Bhattarai, B. Paudel, H.K. Lee, H. Oh, J.H. Yim, "In vitro Antioxidant Capacities of Two Benzonaphthoxanthenones: Ohioensins $\mathrm{F}$ and $\mathrm{G}$, Isolated from the Antarctic Moss
Polytrichastrum alpinum", Zeitschrift für Naturforschung, vol. 64c, pp. 197-200, 2009. DOI: 10.1515/znc-2009-3-408

[58] S. Talai- Mukhopadhyay, S. Mitra, A. Biswas, N. Das, M. Poddar- Sarkar, "Screening of Antimicrobial and Antioxidative Potential of Selected Eastern Himalayan Mosses", European Journal of Medicinal Plants, vol. 3, no. 3, pp. 422-428, 2013. DOI: 10.9734/EJMP/2013/3164

[59] B. Pejin, J. Bogdanovic- Pristov, I. Pejin, M. Sabovljević, "Potential antioxidant activity of the moss Bryum moravicum", Natural Product Research, vol. 27, no. 10, pp. 900-902, 2013. DOI: $10.1080 / 14786419.2012 .665915$

[60] R. Mishra, V.K. Pandey, R. Chandra, "Potential of bryophytes as therapeutics", International Journal of Pharmaceutical Sciences and Research, vol. 5, no. 9, pp. 3584-93, 2014. DOI: 10.13040/IJPSR.0975-8232.5

[61] F. Abdul- Karim, M. Suleiman, A. Rahmat, M.F. Abu- Bakar, "Phytochemicals, antioxidant and antiproliferative properties of five moss species from Sabah, Malaysia”, International Journal of Pharmacy and Pharmaceutical Sciences, vol. 6, no. 10, pp. 292-297, 2014.

[62] V. Singh, A. Alam, A. Sharma, "Evaluation of Phytochemicals, Antioxidant and Antibacterial Activity of Hyophila involuta (Hook.) Jaeg. and Entodon plicatus C.Muell. (Bryophyta) from Rajasthan, India", International Journal of Scientific Research in Knowledge, vol. 4, no. 3, pp. 056-063, 2016. DOI: 10.12983/ijsrk2016-p0056-0063

[63] B. Aslanbaba, S. Yilmaz, Ö. Tonguç-Yayintaş, D. Özyurt, B.D. Öztürkc, "Total phenol content and antioxidant activity of mosses from yenice forest (ida mountain)", Journal of Scientific Perspectives, vol. 1, no. 1, pp. 1-12, 2017. DOI: $10.26900 /$ jsp.2017.0

[64] M.M. Vujičić, S.M. Milošević, M.S. Sabovljević, A.D. Sabovljević, "Effect of ABA 
treatment on activities of antioxidative enzymes in selected bryophyte species", Botanica Serbica, vol. 41(1), pp. 11-15, 2017. DOI: $10.5281 /$ zenodo. 452673

[65] Ö. Tonguç- Yayintaş, O. Sogut, S. Konyalioglu, S. Yilmaz, B. Tepeli, "Antioxidant activities and chemical compositon of different extracts of mosses gathered from turkey", AgroLife Scientific Journal, vol. 6, no. 2, pp. 205-213, 2017.

[66] H. Türker, B. Türkyilmaz Ünal, "Potansiyel Antioksidan Kaynaği Olarak Briyofitler", Anatolian Bryology, vol. 6, no. 2, pp. 129137, 2020. DOI: 10.26672/anatolianbryology.740094

[67] I. Kranner, S. Birtic, "A Modulating Role for Antioxidants in Desiccation Tolerance", Integrative and Comparative Biology, vol. 45, pp. 734-740, 2005. DOI: 10.1093/icb/45.5.734

[68] M. Nagae, M. Nakata, Y. Takahashi, "Identification of Negative cis-Acting Elements in Response to Copper in the Chloroplastic Iron Superoxide Dismutase Gene of the Moss Barbula unguiculata", Plant Physiology, vol. 146, pp. 1687-1696, 2008. DOI: 10.1104/pp.107.114868

[69] A. Basile, S. Sorbo, B. Conte, B. Golia, S. Montanari, R. Castaldo- Cobianchi, et al., "Antioxidant activity in extracts from Leptodictyum riparium(Bryophyta), stressed by heavy metals, heat shock, and salinity", Plant Biosystems - An International Journal Dealing with All Aspects of Plant Biology, vol. 145, no. 1, pp. 77-80, 2011. DOI: $10.1080 / 11263504.2010 .509935$

[70] D. Gahtori, P. Chaturvedi, "Bryophytes: A Potential Source of Antioxidants. Bryophytes" In: Sabovljević M.S., Sabovljević AD, editors. Bryophytes. 1st ed. London: Intechopen, pp. 53-65, 2020. DOI: 10.5772/intechopen.84587

[71] M.F. Abu Bakar, F.A. Karim, M. Suleiman, A. Isha, A. Rahmat, "Phytochemical Constituents, Antioxidant and Antiproliferative
Properties of a Liverwort, Lepidozia borneensis Stephani from Mount Kinabalu, Sabah, Malaysia", Evidence-Based Complementary and Alternative Medicine, pp. 1-9, 2015. DOI: 10.1155/2015/936215

[72] S. Mukhia, P. Mandal, D.K. Singh, D. Singh, "Evaluation of anti-diabetic, antioxidant activity and phytochemical constituents of liverworts of Eastern Himalaya", Journal of Chemical and Pharmaceutical Research, vol. 7, no. 10, pp. 890-900, 2015.

[73] J. Morantes, C. Prieto, E. Linares, J. Rincón, F. Aristizábal, "Análisis fitoquímico y de actividad biológica del musgo Polytrichum juniperinum”, Revista de la Academia Colombiana de Ciencias Exactas, Físicas y Naturales, vol. 31, no. 121, pp. 473-479, 2007.

[74] P. Aubad- López, B.A. Rojano, T. Lobo- Echeverri, "Actividad Antioxidante en Musgos", Scientia et Technica, vol. 33, pp. 23-26, 2007. DOI: https://doi.org/10.22517/23447214.5823

[75] J.A. Pereañez, T. Lobo-Echeverri, B. Rojano, L. Vargas, M. Fernández, C.A. Gaviria, et al., "Correlation of the inhibitory activity of phospholipase A2 snake venom and the antioxidant activity of Colombian plant extracts", Brazilian Journal of Pharmacognosy, vol. 20, no. 6, pp. 910-916, 2010. DOI: 10.1590/S0102-695X2010005000030

[76] J.C. Rodríguez-Rodríguez, I.J.P. SamudioEcheverry, L.G. Sequeda- Castañeda, "Evaluation of the Antibacterial Activity of Four Ethanolic Extracts of Bryophytes and Ten Fruit Juices of Commercial Interest in Colombia against Four Pathogenic Bacteria", Acta Horticulturae, vol. 964, pp. 251-258, 2012. DOI: 10.17660/ActaHortic.2012.964.30

[77] W. Brand-Williams, M.E. Cuvelier, C. Berset, "Use of a Free Radical Method to Evaluate Antioxidant Activity", Lebensmittel-Wissenschaft und -Technologie, vol. 28, pp. 25-30, 1995. DOI: 10.1016/s0023-6438(95)80008-5 
[78] N.J. Miller, A.T. Diplock, C. Rice- Evans, M.J. Davies, V. Gopinathan, A. Milner, "A Novel Method for Measuring Antioxidant Capacity and its Application to Monitoring the Antioxidant Status in Premature Neonates", Clinical Science, vol. 84, pp. 407-12, 1993. DOI: $10.1042 / \operatorname{cs} 0840407$

[79] M.B. Arnao, A. Cano, M. Acosta, "Methods to Measure the Antioxidant Activity in Plant Material. A Comparative Discussion", Free Radical Research, vol. 31, pp. 89-96, 1999. DOI: 10.1080/10715769900301371

[80] R.L. Prior, X. Wu, K. Schaich, "Standardized Methods for Determination of Antioxidant Capacity and Phenolics in Foods and Dietary Supplements", Journal of Agricultural and Food Chemistry, vol. 53, pp. 4290-302, 2005. DOI: $10.1021 / \mathrm{jf} 0502698$

[81] Md. N. Alam, N.J. Bristi, Md. Rafiquzzaman, "Review on in vivo and in vitro methods evaluation of antioxidant activity", Saudi Pharmaceutical Journal, vol. 21, pp. 143-152, 2012. DOI: $10.1016 /$ j.jsps.2012.05.002

[82] R. Re, N. Pellegrini, A. Proteggente, A. Pannala, M. Yang, C. Rice-Evans, "Antioxidant Activity Applying an Improved ABTS Radical Cation Decolorization Assay", Free Radical Biology and Medicine, vol. 26, pp. 1231-1237, 1999.

[83] D. Villano, M.S. Fernández-Pachón, A.M. Troncoso, M.C. García-Parilla, "The Antioxidant Activity of Wines Determinated ABTS ${ }^{*+}$ Method: Influence of Simple dilution and Time", Talanta, vol. 64, pp. 501-509, 2004. DOI: 10.1016/j.talanta.2004.03.021

[84] E.P. Labrinea, C.A. Georgiu, "Stoppedflow Method for Assessment of $\mathrm{pH}$ and Timing Effect on the ABTS Total Antioxidant Capacity Assay", Analytica Chimica Acta, vol. 526, no. 1, pp. 63-68, 2004. DOI: 10.1016/j.aca.2004.09.040

[85] D. Huang, B. Ou, R.L. Prior, "The Chemistry behind Antioxidant Capacity Assays", Journal of Agricultural and Food Chemistry, vol. 53, pp. 1841-1856, 2005. DOI: 10.1021/jf030723c

[86] A. Zuleta, M. Esteve, A. Frigola, "ORAC and TEAC assays comparison to measure the antioxidant capacity of food products", Food Chemestry, vol. 114, pp. 310-316, 2009. DOI: 10.1016/j.foodchem.2008.09.033

[87] S. Beckert, S. Steinhauser, H. Muhle, V. Knoop, "A molecular phylogeny of bryophytes based on nucleotide sequences of the mitochondrial nad5 gene", Plant Systematics and Evolution, vol. 218, pp. 179-192, 1999.

[88] K. Renzaglia, S. Schuette, R.J. Duff, R. Ligrone, A.J. Shaw, B.D. Mishler, et al., "Bryophyte phylogeny: Advancing the molecular and morphological frontiers", The Bryologist, vol. 110, no. 2, pp. $179-213$, 2007. DOI: 10.1639/00072745(2007)110[179:BPATMA]2.0.CO;2

[89] T.C.H. Cole, H.H. Hilger, B. Goffinet, "Bryophyte Phylogeny Poster (BPP) PeerJ Preprints”, 2019. DOI: 10.7287/peerj.preprints.27571v3/supp-1

[90] S. Vats, A. Alam, "Antioxidant activity of Barbula javanica Doz. et Molk.: A relatively unexplored bryophyte", Elixir Appl. Botany, vol. 65, pp. 20103-20104, 2013.

[91] M.M. Makajanma, I. Taufik, A. Faizal, "Antioxidant and antibacterial activity of extract from two species of mosses: Leucobryum aduncum and Campylopus schmidii", Biodiversitas, vol. 21, pp. 2751-2758, 2020. DOI: 10.13057/bio$\operatorname{div} / \mathrm{d} 210651$

[92] G.G. Mohandas, M. Kumaraswamy, "Antioxidant Activities of Terpenoids from Thuidium tamariscellum (C. Muell.) Bosch. and Sande-Lac. a Moss", Pharmacognosy Journal, vol. 10, no. 4, pp. 645-649, 2018. DOI: 10.5530/pj.2018.4.106

[93] Y. Asakawa, F. Nagashima, T. Hashimoto, M. Toyota, A. Ludwiczuk, I. Komala, T. Ito, Y. Yagi, "Pungent and Bitter, Cytotoxic and 
Antiviral Terpenoids from Some Bryophytes and Inedible Fungi", Natural Product Communications, vol. 9, no. 3, pp. 409-417. 2014. DOI: $10.1177 / 1934578 \times 1400900331$

[94] J.A. López- Saez, "Flavonoides en Bartramiaceae Schwaegr (Musci, Bryophyta): Aspectos quimiosistemáticos y actividad biológica", (Tesis Doctoral), Universidad Complutense de Madrid. Madrid, 354, pp. 1994.

[95] J.A. López-Saez, J. Pérez-Alonso, A. Velasco Negueruela, "Contribution to the phylogeny of Philonotis Brid. (Bartramiaceae Schwaegr.): Flavonoids of sections Catenularia (O Mliii.) Par and Euphilonotis Limpr.", Botanica Complutensis, vol. 21, pp. 51-58. 1996.

[96] J.A. López-Saez, "A Revision of the Taxonomic Status of Bartramia rosea and B. ruwenzoriensis (Bartramiaceae) Based on Flavonoid Composition" The Brvologist, vol. 99, no. 3, pp. 328-330. 1996.

[97] O. Üçüncü, T.B. Cansu, T. Özdemir, Ş. Alpay Karaoğlu, N. Yayli, "Chemical composition and antimicrobial activity of the essential oils of mosses (Tortula muralis Hedw., Homalothecium lutescens (Hedw.) H. Rob., Hypnum cupressiforme Hedw., and Pohlia nutans (Hedw.) Lindb.) from Turkey", Turkish Journal of Chemistry, vol., 34, pp. 825-834. 2010. DOI: 10.3906/kim-1002-62

[98] K. Sievers, B. Gunther, H. Becker, H.D. Zinsmeeter, "Hypnogenols and other dihydroflavonols from the moss Hypnum cupressiforme", Phytochemistry, vol. 31, no. 9, pp. 3233-3237. 1992.

[99] J.A. López- Saez, J. Pérez- Alonso, A. Velasco Negueruela, "Flavonoides en Musgos: consideraciones quimiosistemáticas", Botanica Complutensis, vol. 21, pp. 9-38. 1996.

[100] T.M. Lunić, M.M. Oalde, M.R. Mandic, A.D. Sabovljević, M.S. Sabovljević, U.M. Gašić, S.N. Duletić-Laušević, B.Dj. Božić, B. Dj. Božić, B. Dj. Nedeljković, "Extracts Characterization and In Vitro Evaluation of Potential Immunomodulatory Activities of the Moss Hypnum cupressiforme Hedw. Molecules", vol. 25, pp. 33-43. 2020. DOI: 10.3390/molecules 25153343

[101] Ö. Tonguç- Yayintaş, D. Alpaslan, Y. Karagul Yuceer, S. Yilmaz, N. Sahiner, "Chemical composition, antimicrobial, antioxidant and anthocyanin activities of mosses (Cinclidotus fontinaloides (Hedw.) P.Beauv. and Palustriella commutata (Hedw.) Ochyra) gathered from Turkey", Natural Product Research, vol. 31, no. 18, pp. 2169-2173. 2017. DOI: $10.1080 / 14786419.2016 .1277355$

[102] F. Chen, A. Ludwiczuk, G. Wei, X. Chen, B. Crandall- Stotler, J.L. Bowman, "Terpenoid Secondary Metabolites in Bryophytes: Chemical Diversity, Biosynthesis and Biological Functions", Critical Reviews in Plant Sciences, pp. 1-22. 2018. DOI: 10.1080/07352689.2018.1482397

[103] J. Li, L. Wei, C. Chen, D. Liu, Y. Gu, J. Duan$\mathrm{Mu}, \mathrm{G}$. Chen, Y. Song, "Biological metabolites from the bryophyta Hypnum plumaeforme Wilson", Chemistry \& Biodiversity. DOI: 10.1002/cbdv.202000552

[104] A. Ludwiczuk, Y. Asakawa, "Terpenoids and Aromatic Compounds from Bryophytes and their Central Nervous System Activity", Current Organic Chemistry, vol. 24, no. 1, pp. 113-128. 2020. DOI: $10.2174 / 1385272824666200120143558$

[105] E. Valarezo, V. Vidal, J. Calva, S.P. Jaramillo, J.D. Febres, A. Benitez, "Essential Oil Constituents of Mosses Species from Ecuador", Journal of Essential Oil Bearing Plants, vol. 21, no. 1, pp. 189-197. 2018. DOI: 10.1080/0972060x.2018.1432420

[106] M. Commisso, F. Guarino, L. Marchi, A. Muto, A. Piro, F. Degola, "Bryo-Activities: A Review on How Bryophytes Are Contributing to the Arsenal of Natural Bioactive Compounds against Fungi”, Plants, vol. 10, pp. 203-230. 2021. DOI: $10.3390 /$ plants 10020203 
[107] A. Seyoum, K. Asres, F. Kandeel ElFiky, "Structure-radical scavenging activity relationships of flavonoids", Phytochemistry, vol. 67, pp. 2058-2070. 2006. DOI: 10.1016/j.phytochem.2006.07.002

[108] O. Cartaya, I. Reynaldo, "Flavonoides: Características químicas y aplicaciones", Cultivos Tropicales, vol. 22, no. 2, pp. 5-14. 2001.

[109] S.Q. Sun, M. He, T. Cao, Y. Zhang, W. Han, "Response mechanisms of antioxidants in bryophyte (Hypnum plumaeforme) under the stress of single or combined $\mathrm{Pb}$ and/or Ni", Environmental Monitoring and Assessment, vol. 149, pp. 291-302, 2009.

[110] K. Peters, H. Treutler, S. Döll, A.S.D. Kindt, T. Hankemeier, S. Neumann, "Chemical Diversity and Classification of Secondary Metabolites in Nine Bryophyte Species", Metabolites. vol. 9, no. 10, pp. 222, 2019. DOI: 10.3390/metabo9100222

[111] M.C.F. Proctor, "The physiological basis of bryophyte production", Botanical Journal of the Linnean Society, vol. 104, pp. 61-77, 1990.
[112] X. Zhang, Y. Zhao, S. Wang, "Responses of antioxidant defense system of epilithic mosses to drought stress in karst rock desertified areas", Acta Geochimica, vol. 36, no. 2, pp. 205-212, 2017. DOI: $10.1007 / \mathrm{s} 11631-017-0140-\mathrm{z}$

[113] A. Baxter, R. Mittler, N. Suzuki, "ROS as key players in plant stress signaling", Journal of Experimental Botany, vol. 65, no. 5, pp. 12291240, 2013. DOI: $10.1093 / \mathrm{jxb} / \mathrm{ert} 375$

[114] W.E. Seel, G.A.F. Hendry, J.A. Lee, "Effects of Desiccation on some Activated Oxygen Processing Enzymes and Anti-Oxidants in Mosses", Journal of Experimental Botany, vol. 43, no. 253, pp. 1031-1037, 1992.

[115] X. Wang, J. Cao, X. Dai, J. Xiao, Y. Wu, Q. Wang, "Total flavonoid concentrations of bryophytes from Tianmu Mountain, Zhejiang Province (China): Phylogeny and ecological factors", PLoS ONE, vol. 12, no. 3, pp. 1-10, 2017. DOI: 10.1371/journal.pone.0173003 